\title{
Construction Process and Its Enlightenment to China on Social Innovation System of the United States and Japan
}

\author{
Jiaqi Chen \\ College of Economics and Law, Bohai University, Jinzhou, 121013, China \\ jackie@bhu.edu.cn
}

\begin{abstract}
Keywords: social innovation system; industrial laboratory; technological progress; research and development institutions
\end{abstract}

\begin{abstract}
The development of both the developed countries United States and Japan shows that social innovation system plays an important role in the process of them from weak to strong. The United States in the process of industrialization, the main body of technological innovation is scattered on the enterprise internal industrial research laboratories, this becomes a main reason for America's development as the world's leading economic power. In Japan society for the construction of innovation system has the similar experience. Composed of numerous industrial laboratories and research institutions in social innovation system is very effective for all kinds of innovation. Industrial research laboratories between different associations for cooperation on a particular field can develop different types of hybrid technology. The United States and Japan's experience to the construction of innovation system of Chinese society has positive significance.
\end{abstract}

\section{Introduction}

The development of the national economy by relying on nothing more than a few enterprises of several technological innovation is not enough, only show the strength of the entire society all aspects, the innovation of the application as much as possible, to constantly improve the level of productivity of the whole society, so countries in encouraging companies to cultivate innovation ability at the same time, also attaches great importance to the scientific research institutes, institutions of higher learning all the specializing in the development of innovative technology research unit, establish a scientific research units to industry department's effective social innovation system, both to clear the purpose of technology innovation, and can speed up the transformation of scientific and technological achievements into realistic productivity. In many developed countries in the process of its industrialization, in terms of the establishment of a social innovation system has a wealth of experience is worth our using for reference.

\section{Establishment of American Social Innovation System}

The United States in the process of industrialization, the main body of technological innovation is scattered on the enterprise internal industrial research laboratories, even now, the United States 80 percent of science and technology research and development is also in industrial research laboratory. After discovering the new continent, immigrants came to America in neither how many intellectuals, scientists, and there are few experienced entrepreneurs and managers of the country, so the United States was originally by small craft owners, technicians, landowners, farmers and slave nation. Although before the civil war, the United States has built nearly a century of higher schools, but there's no research institutions and less scientific management authority. In 1863, President Lincoln established under the sponsorship of the national academy of sciences, in order to provide consultation for government departments, which later became the core of the scientific research institutions. Industrialization to improve the production efficiency of infinite demand, directly led to the invention to the creation of application technology of the birth of industrial laboratory. U.S. industrial research laboratory for the development of four stages: the first stage in 1876 marked the establishment of the Edison's Menlo park laboratory, this stage of the technology innovation is based on experience of repeated tentative research activities; The second stage is the industrial 
research laboratories founded in 1900, general electric marked, its characteristic is based on available scientific knowledge in the technological innovation activities, the laboratory is given priority to with scientists and engineers, and separated from the production and marketing of enterprise internal departments, form the relatively independent research and development institutions; The third stage is the telegraph and telephone company established in 1925 for industrial research lab, lab during this period is based on scientific knowledge in technological innovation activities, so the laboratory not only have a series of important scientific discoveries in basic research, and on the technology and products also made an important invention innovation; The fourth stage is the period after 1985, as the market competition, many small and medium-sized enterprises from basic science research, industrial research laboratory to union university established in common science and technology innovation activities.

From weak to strong development process in the United States, the United States industrial research laboratory and a growing number of research and development funds rising, new technology constantly emerging, an uptick in gross national product. Because of the U.S. government for industrial research laboratory and the number of personnel statistics began from 1920, so we study data can be seen after 1920 the trend of development.

In 1920, the industrial research lab number is 296, the $\$ 029$ million of funds for research. To the front of the World War Two, number increased to 1769, industrial laboratory research budget of $\$ 200$ million. After the World War Two and further development, industrial laboratory number for 2500 , 1950, the $\$ 1.59$ billion of funds for research. In the $80 \mathrm{~s}$, industrial laboratory data of 9600 , funds of $\$ 69$ billion. The above statistics show that the number of U.S. industrial research laboratory, research and development funds, on behalf of innovations and GDP growth is an increase of the number of patents, there is a strong positive correlation between them. Even in 1930, the American social innovation activities have not weakened because of the economic crisis. It is because of the industrial research lab based social innovation system, the establishment of the United States will become the world's leading economic power. After world war ii, Stalin regrets ground say: "the cause of the allied victory in the world war ii, not because the number of infantry regiment, not because of the plane, also not because of the tank, but because of the great American industrial machine, this machine is made up of various parts in this great country thousands of laboratory support."

\section{Establishment of Japanese Social Innovation System}

Japan in the early stage of industrialization, the Meiji government intended to through the introduction of technology, to establish several large projects makes Japan become overnight industrialized countries, but by the early $1880 \mathrm{~s}$, they had to give up the idea, to take the initiative to local technology program to provide legal and economic aid, to encourage local laboratory construction. Agricultural business province began to send adviser in the $1880 \mathrm{~s}$. It helped by local government established various technical center and in 1901 issued a unified standard for laboratory and technology education center at the county level and the rules of law. The government also introduced a law in 1903, encourage and regulate the establishment of the institute of technology. 1905 farming business ministry approved a modest funding support for local experiments. The first year of funding totaling 15000 yen, assigned to 11 local research laboratories. To the end of the Meiji grants has doubled, the number of funded institutions also increased to 14 . To the beginning of the 20th century, the Japanese government through intervention began to the local government on the technological introduction and innovation efforts into the national system of industrial research. In such a system, the introduction and innovation of technology and acacia not only lies in the controlled by the government or private enterprise a few elite group's hands, but scattered in a wide range of size, structure, and the geographical position different research institutions and economic entity, and these institutions and entities are not isolated movements, but through a variety of communication channels together, form a social innovation network. The Meiji era of the social networks of technology innovation is not only promoted the rapid development of innovation, 
but also to create a distinctive innovation model, this model directly influenced the Japanese process of technical progress in the future.

At the beginning of the 20th century, more and more Japanese companies as the main body of technology import, while the introduction of technology through simple imitation cannot master, only those with modern scientific theory foundation for man can grasp, so many enterprises in order to grasp, absorb and make use of the introduction of new technology and industrial laboratories are established within the enterprise. From the Meiji period until the 1930 s, Japanese industrial laboratories founded enterprise internal number about 300. Private laboratories founded enterprises got the support of public laboratories founded in Meiji period, the research university and the other is funded by the government laboratory provides a guide to private enterprises, so some of the most important industries in Japan under strong technical director of the institute for the study of rapid development. In order to further promote the construction and to encourage invention and innovation of private industrial laboratory, 1917 the Japanese government has implemented a formal reward the inventor of the system. In 1926 the government began to provide subsidies to support private industry research laboratory research work. Established in 1932, the Japanese government to follow other industrialized countries a wider encourage research system. Funded by the royal family and or established Japanese council for the promotion of science, every year in the $30 \mathrm{~s}$ to 25 to 500000 yen in funding academic research, and provides the same number for the social sciences and humanities. From 1926 to 1937, the Japanese government offer inventors and private research laboratory, a total of 2.13 million yen, encourage 1040 invention plans, including 1937 invention plan is more than three times in 1926. By 1942, Japan has about 1150 industrial research laboratories and half of them are corporate laboratories, the number of researchers also increased from 1935 in 28000 to 1935. Late 30 s, many Japanese companies started from the imitation of imported technology to develop original production technology, and has strengthened the importance of basic research. Such as Toyota motor corp., in 1940 set up his own Toyota institute of physics and chemistry; Hitachi in the same year set up a large central research laboratory, is mainly engaged in basic science and applied science and technology research.

After the World War Two, the establishment of a new batch of local research laboratory is one of the main purposes of the Japanese local industry recovery policy. From 1945 to 1960, Japan, a total of 23 new local research laboratories, most research laboratory has focused on the development of the post-war promising industry, such as machinery manufacturing. In 1961 the Japanese government also launched a encourage private enterprises to establish a cooperation association for the study of policy, and the association to tax reductions. 1960 Japan has more than 6500 enterprises engaged in industrial technology research activities, all of the research of 89 percent relative larger companies from more than 2900, and the remaining 11 percent split between more than 3600 small businesses. In 1961 the Japanese government in 783 controls the 159 industrial research laboratory in colleges and universities, as well as more than a government laboratories specializing in agriculture and medicine research. Almost all the industrial research laboratory is directly related with the private sector.

Composed of numerous industrial laboratories and research institutions in social innovation system is very effective for all kinds of innovation. Industrial research laboratory to between different association for cooperation on a particular field to develop different types of hybrid technology, which is embodied in such as mechanical and optical electronic need special technical knowledge combined with the technical development. Based on the same basic technology and a slightly different pattern between industries, there is a competition with each other, in the field of such innovation, social innovation system is very suitable in Japan, the performance of TV and computer manufacturing industry in Japan.

\section{Should Solve Problems in Establishment of Chinese Social Innovation System}

China's future economic development must rely on the improvement of overall level of social productive forces, and it must be under the perfect social innovation system to complete, so the Chinese government now faces an important task is to establish and perfect social innovation 
system of China. The United States, Japan's social experience for the construction of innovation system in our country present stage social innovation system construction has important reference value.

Chinese enterprises' innovation capability is not strong is indisputable fact that the technology level of enterprises and enterprise is a big gap with the developed country, so in the future for a long period of time, technology import and purchase of the patent right will be the main way of technological progress of Chinese enterprises. In such a case, the government should establish incentive mechanism and encourage enterprises to carry out research and development of enterprise internal organization construction. Within the enterprise research and development institutions not only for the imported technology digestion, absorption, transformation and innovation of work, but also part of the application technology research and development, gradually has the fundamental development of the enterprise by human power management to research and development center construction and development. To establish the incentive mechanism of government should use fiscal policy to give priority to, namely the means such as tax breaks or to provide financial assistance is given priority to, should not be planned economy mode of executive orders.

At the same time of strengthening the construction of enterprise internal research and development institutions, the government should also strengthen the construction of existing research institutions. Around inside colleges and universities and research institutes of various areas are an important force in China's scientific and technological innovation, the government should increase the investment in such research institutions, to promote their innovation ability. At the same time the government strengthen the application of technology innovation investment at the same time, should also strengthen the investment in basic scientific research. Basic scientific research experiment is scientific research of the technological innovation, in particular, for any country in the technology and products on significant and revolutionary achievements, to the innovation on the basis of the new technology in the breakthrough of scientific research, will have an irreplaceable role. Whether American technology development pattern or mode of the development of science and technology, Japan is not by weakening the basic scientific research to strengthen technical innovation, but at the same time in the development of enterprise technology research and development of gradually strengthening basic scientific research, the experience is very noticeable. The central government at the same time of strengthening the construction of scientific research institutes and actively play the role of local government, accelerate the construction of local institutions, to meet the needs of the local small and medium-sized enterprise development of technology. Dr. Yang said: most of the major scientific and technological innovation is not the result of research, but by skirmisher fight to win. So the priority support several scientific research institutions of the central government alone for several important scientific research, to improve overall level of the production of the whole society is not necessarily the best way.

Strengthen the collaboration between various research institutions, scientific research institutions of dispersion system integration plays to the overall strength of scientific research institutions is the government in building the innovation system of important work to do. In our country now the social innovation of system, low efficiency of the system integration, enterprises, research institutes, institutions of higher learning, and other subsystems disjointed, not form a running system effectively. Within each subsystem has formed a considerable strength, but the officer, production, study, or lack of close cooperation between production, study and research, don't mix. Officer, the result of the close cooperation between production, study and research, not only can make the innovation ability enhancement, but also can accelerate the diffusion of new technology, can make the overall level of social productive forces in a relatively short period of time to improve quickly.

\section{Conclusion}

The government's need to do is to market regulation as the means, supplemented by policy guidance, closely officer, the cooperation among production, study and research, make social innovation system to spurt the energy more. But the government must not violate the market rules, executive 
orders general officer, such as production, study and research to bunched together, it not only won't produce force, but also affects each department of independent innovation.

\section{References}

[1] J. C. Zhao, Z. X. Zhang, et al., "Technology innovation principle and system construction," Henan People’s Publishing House, pp. 33-58, 2002.

[2] K. N. Yan, "The road to the new economy," Oriental Press, pp. 125-157, 2000.

[3] Y. H. Wang, "Research on technology innovation model of Japanese industrial enterprises," Chinese Journal of Management Science, vol. 2, no. 4, pp. 25-32, 1994.

[4] X. Long, "The Japanese government's support for the high-tech industry and macroeconomic regulation and control," Scientific Management Research, vol. 1, no. 1, pp. 19-21, 1997.

[5] William Baumol, "The growth miracle of capitalism," China Citic Press, pp. 167-182, 2004.

[6] West Gefade Harrison, "Japan's technology and innovation management," Peking University press, pp. 81-121, 2004. 